\title{
Science in Japan.
}

By Prof. C. Coleridge Farr, Christchurch College, Canterbury, N.Z.

A S a delegate from the New Zealand Institute I had the honour and great pleasure to visit Japan on the occasion of the third Pan-Pacific Scientific Congress which was held there in October and November last, and an account of that visit may be of interest. As a physicist, and from a scientific point of view, I confined my attention solely to physics, geophysics, and cognate branches of knowledge; and I must leave other delegates to make such remarks as they may think necessary on the branches of science which interested them. Before dealing with the main subject of this article, however, I desire to make several observations of a general character.

Organisation.-The organisation of the meeting was remarkable for its completeness and thoroughness, and is a great credit to those who had to do with its development. On entering Japanese waters at Nagasaki, a port at least 850 miles from the city of Tokyo, where the meeting was held, we were met by an emissary from the Conference, Dr. Oshima, and from then until the mornent of sailing again from the same port four weeks later, we were not without the assistance of honorary guides, who were Japanese gentlemen who could speak English fluently. I believe similar guides met every party arriving from oversea at their port of arrival, and that each party was also 'shepherded' in the same way as we were throughout the tour. The amount of strenuous effort on the part of the guides must have been tremendous. They took control of all the baggage-and I did not hear of a single instance of loss - they made all the necessary arrangements regarding sleeping berths in the trains, they provided meals where the travelling was done in trains which had no dining-car-in fact they saw to all details, and seemed to leave nothing whatever to chance. The benefit of this in a land with a foreign and absolutely unknown language cannot be imagined, and only became apparent to us on those occasions when-breaking away from our guides -we attempted to make our own way about in some of the cities. Progress then, if not impossible, became exceedingly slow. The people one met were courtesy itself but could not understand what we wanted, nor could we understand their answers, and it was therefore necessary to light at length upon some person who did understand something of the language one was speaking.

In all other respects the organisation of the meeting was at an equally high level.

JaPANese Courtesy.-Perhaps it may not be out of place to make a few observations upon this delightful feature of Japanese life which impressed itself upon so many of us upon numerous occasions. The Japanese seem-as was stated by a speaker at one of the functions that were held-to be a nation of gentlemen. They appear to be as courteous amongst themselves as they certainly were to us. One could notice the most polite meetings and partings of Japanese who did not know they were being observed. The school children that one met-and they were everywhere to be seen-were friendly and orderly amongst themselves, and prettily responsive to greetings from us. I heard of no unpleasant incident, but I myself had many examples of courtesy which would be exceptional in some other parts of the world. Not once or twice, but many times, have I asked my way to a place from a person who understood what I wanted but whose answer I was unable to comprehend. On every such occasion he would answer, "I will show you," and would go perhaps half a mile out of his way to do so. Or if a rikisha or motor-car was available he would call it and give directions to the man. Courtesy seems to be a natural and very pleasant trait in Japanese character.

Scientific Aspects of the Meeting.--If the Congress left anything at all to be desired it was more time for the reading and discussion of papers. In all, some four hundred papers were sent in, which had to be got through in ten days. This necessitated very strict time limits being imposed upon authors and speakers, and it was a very exceptional paper that could be given more than ten minutes. Though no doubt it would be well to have more time, yet such restriction is not so bad as it might seem. Fairly complete abstracts were available, and were often read in place of the paper. These abstracts were printed and distributed on the morning or afternoon that any particular paper came on, and it could thus be seen in advance what the paper was about, and as all the delegates were staying at the same hotel in Tokyo, there were many other opportunities for discussion. It was in the hotel that some of the most valuable discussions took place, between perhaps the author of a paper and others who were interested. It is often the case in scientific meetings such as this, that informal discussions arising out of papers read are more productive of good than the actual hearing of the papers. To appreciate fully the work described by an author in a written paper, it is necessary to read and study the paper, and in physical and mathematical papers it is frequently important to work out anew the author's mathematical reasoning. For this the publication of the paper is essential, and in the present case most, if not all, of the papers read will in due course be published. Thus although the number of papers offered was very large for the time available, yet I think all the delegates felt that this did not militate against the success of the meeting to the extent which it might have been expected to have done by those who were not present. In future meetings it may perhaps be well if a previous censorship of papers is instituted, so that only those of outstanding importance shall be read.

Constitution OF THE CONGRess.-Until the present meeting, I believe the meetings of the congress have been conducted without any very definite constitution or by-laws, much being left to the president, and to the discretion of those organising the next forthcoming meeting - that is to say, to the local organising committee at the place of meeting. At the Tokyo meeting, however, a definite constitution and by-laws were drawn up and received the approval of the conference as a whole. By this constitution the name of the conference is now "The Pacific Science Association," and its meetings are to be held at intervals of not less than two or more than five years. The constitution consists of fifteen clauses, of which Clause 4, relating to the constitution of the Council, is probably the most interesting and important from the point of view of the New Zealand Institute. The administrative work of the association is arranged to be carried on by a council of not more than fifteen members, the seats being allotted to 'Countries' of which eleven or twelve are named in the constitution, leaving three or four vacancies for countries that may at some future time desire to come in. The countries so far named are the United States of America, Canada, Australia, France, Great Britain, Hawaii, Japan, Netherlands, Netherlands East Indies, New Zealand, Philippine Islands, and Russia, and these countries are to be represented on the council each by one 
member, who is to be elected by its National Research Council, or by some other scientific organisation of recognised standing. The scientific bodies thus having electoral powers are named in the constitution, and in the absence at present of a National Research Council, the New Zealand Institute has been named for New Zealand.

Amongst the by-laws, which consist of fourteen articles, there is one (Art. 7) for which perhaps we may be grateful. It provides that the usual language of the congress shall be English.

VIsITs To ScIENTIFIC Instixutions.--This journey to Japan presented exceptional opportunities for visiting and obtaining information about the activities of any particular scientific institution there in the work of which one might be interested. In most cases visits of a large body of delegates to these institutions was a part of the programme of the Congress, but at such visits the greatness of the numbers present prevented many questions being asked, or much individual attention being given to any particular visitor. They were, however, most valuable, as they showed all who took part in them how much Japan is doing in the cause of science. One had, moreover, only to express a wish to see any particular institution and a more or less private inspection of it was most willingly and most courteously arranged. In this more complete way I was enabled to see some most interesting organisations, the work of some of which will now be referred to.

Aeronauticat Research Institute, Tokyo.This institute is, and always has been, a part of the Imperial University of Tokyo. The first of the ordinances which govern it states that the Aeronautical Research Institute shall be attached to the Tokyo Imperial University, though its present location is some miles from what is actually the Imperial University building. It concerns itself with the investigation of all subjects relating to aeronautics, a term which it wisely interprets in a very broad manner. It is a development of the Investigation Committee on Aeronautics which was founded under the chairmanship of Dr. A. Tanakadate in 1916. The Research Institute dates from 1918, and, like most other Tokyo institutions, was very seriously damaged by the 1923 earthquake. It is, however, rebuilt sufficiently to enable work to be carried on there pending the completion of a much larger and more complete institution at another part of the city. Much might be said about this institution, but here only a few of the points which were most interesting to myself can be referred to. The work of the institute is divided into twelve departments, which are as follows: Physics, chemistry, metallurgy, materials, wind tunnel, aero engines, aircraft, instruments, aeronautical psychology, central library, workshop, and office.

It will be seen that at the head of this list of departments, which is taken as it stands out of a report of the Institute, the fundamental sciences of physics and chemistry are recognised as of the first importance to progress. This is the case in all the Japanese research establishments of this nature, and there are very many of them. Without progress in the fundamental sciences, progress in the applications is impossible. The whole institution is under the general control of Baron Shiba. The liberal staffing of the various departments is worthy of more than passing notice. Thus the physical department has five chief investigators, nine senior assistants, seven junior assistants, and two laboratory attendants. The chemical department has seven chief members, one senior assistant, five junior assistants, and one laboratory attendant. The aero-engine department has eight chief investigators, twelve senior assistants, fifteen junior assistants, and twenty-two laboratory attendants, and so on throughout the whole of the Institute. The subjects under investigation at present are some nineteen in number in the physical department, nine in chemistry, five in metallurgy, two in materials, seven in the wind-tunnel department, thirty-three in the aero-engine department, eleven in the aircraft department, five in the instrument department, and seven in the aeronautical psychology department, making in all about a hundred different subjects which are under investigation in this one Institute of Aeronautical Research alone. Many researches have been completed and have led to results of great value, and one finds amongst these such subjects as the transverse vibrations of elliptic and rectangular plates, the content of helium and other constituents in the natural gases occurring in Japan, and many others. The bearing of the first of the subjects mentioned is of course in connexion with the vibrations of aeroplane wings, and that of the second with the inflation of dirigible balloons. One must visit Japan to realise what is being done in institutions like this ; institutions, that is to say, the whole object of which is research.

It is here and at similar places that every advance in scientific method is examined, and if possible some application of it is made to the practical problems under consideration. The remotely, or seemingly remotely, connected subject of piezo electricity finds a most valuable use in the investigation of the pressure of piston rings and the wearing of cylinder walls. Electric valves find an application here to the examination of the rate of dissemination of the gaseous charge to different parts of the cylinder, and it may be that some alteration in the design of the form of the cylinder from the old cylindrical shape to some other in which the charge is spread more quickly and more uniformly throughout it may result from this work. Very much more could be said about this interesting establishment at which, owing to the courtesy of Baron Shiba, I was able to spend an all too short morning, but it is, after all, only one of many other similar places, and I must refer to some of the others.

The Institute of Physical and Chemical ReSEARCH.-Perhaps the best way to begin my remarks upon this will be to quote from a pamphlet which was published this year concerning it : "The Institute conducts investigations in the pure sciences of physics and chemistry, aiming at their industrial development, and at the same time engaging in applied research. No undertaking, whether it be in industry or agriculture, would be able to attain sound development unless it was based on physics and chemistry. Particularly in such a densely populated country as Japan, where industrial materials as well as other commodities are not ample, it is essential to aim at the development of industry by having recourse to science, thereby promoting national interests. The object of the institute is to perform this important mission.

"When any physico-chemical applied research is completed in the laboratory it is tested for its in. dustrial applicability, and in case the test shows an appropriate result, arrangement for manufacture is carried out at the Institute ; or the manufacture may be entrusted to others ; or a new company may be established on the basis of a remunerative contract with the Institute, depending upon the nature of the work. At present there are several undertakings that have already existed as industries or are going to exist as such. As the fundamental cause of success in these applied researches lies in there being sound

No. 2993, VoL. 119] 
scientific investigations at the back of them, a part of any profit accruing to the Institute is allotted to the investigation expense of pure science and a further part is given as a reward to the inventor or discoverer."

The staff of this institute numbers 384 , of whom 216 are directly engaged in the investigations; the number of distinct lines of research pursued is, this year, 171 , whilst last year it was 154 . The results of the researches are published, very often in the English language, but they do not appear, as a rule, in any of the more generally recognised scientific journals which we see, at any rate in New Zealand.

Glancing through a list of the investigations, one would scarcely realise that this Institute of Physical and Chemical Research is, like the Aeronautical Research Institute, utilitarian in its work. But the Japanese have realised that for the industries to attain a sound development it is an absolute essential that they should be based upon the fundamental sciences of physics and chemistry, and that any advance in these means a hundredfold corresponding advance in the industries and in agriculture. They therefore interpret the charter in the broadest possible spirit, and amongst the 171 distinct investigations in progress in the Institute there are to be found those relating $(a)$ to the transmutation of mercury into gold; (b) the calculation of mutual and self inductance; (c) photo elasticity ; (d) the manufacture of synthetic sake; (e) the by-products derivable from waste human hair, and 166 others. The greatest freedom is given to the investigators in their work; they are free to undertake or reject any proposed problem. They are experts in their work, and are treated as such, but they receive some benefit of a financial kind for any practical applications of their work. I had the benefit of spending an afternoon at this most interesting institution, and was most kindly shown round by Prof. Nagaoka, whose scientific reputation is very well known, and by Viscount Okochi, who is the superintendent and director of it.

The time available was of course much too short to appreciate all or nearly all that was going on, and very little of the work could really be seen; but what I did see showed how complete and efficient the methods of investigation were, and what a valuable stream of knowledge is issuing from it.

The Institute was founded only nine years ago and its income is derived from an endowment of more than $£ 600,000$, about one-sixth of which was an Imperial gift, a third was a government subsidy, and the other half consisted of contributions from official sources as well as from individuals. The income is now no doubt being augmented by its interest in the rights of some 140 patents which have been obtained as the result of investigations carried out at the establishment.

The Research Institute for Iron, Steel, and other Metals at SendaI.-It is a remarkable thing, and one to be noticed, that many of the 'practical' research institutions of Japan are connected with universities. The Iron and Steel Institute is a part of the Imperial University at Sendai, and the Aeronautical Institute is part of the Imperial University of Tokyo, whilst the Institute of Physical and Chemical Research is closely connected with the Imperial University at Tohoku. This fact becomes more and more impressive the more of these institutions one is able to obtain information about. The Iron and Steel Institute began in a somewhat small way in 1915 to deal with problems arising out of the War, but its scope has been rapidly enlarged, until in 1924 its staff was seemingly about 54 persons, namely, 22 experts and 32 assistants, with Prof. Honda, a man whose reputation has been recognised in Europe for many years, at their head. The research staff consists of twenty members, all of them men of distinction and learning.

Forty-one problems have been the subjects of investigation since September of last year, of which a few may be enumerated, though these are picked at random from the list: $(a)$ The viscosity of molten metals and alloys; $(b)$ comparative investigation of hardness testers ; $(c)$ investigation of magnetic sands ; (d) the effect of sulphur on iron and steel. The Institute publishes its results-or at least some of them-in the Science Reports of the Tohoku Imperial University, in European languages, and has thus published in some accessible European language no less than 140 papers. The knowledge contained in these papers must be a very mine of information for those engaged in metallurgical questions, and it speaks most eloquently for the broadness of the view that the Japanese adopt, that they have published these papers in a European language, as indeed they do most of their papers in every institution. In the vast majority of cases the language used in recent years is English.

The regulations with regard to patent rights arising from work done in the Institute are well worthy of study, especially as similar questions will crop up in connexion with the Department of Industrial Research which is about to be established in New Zealand.

The Geophysical Laboratory at Beppu.-This laboratory, which is a part of the Imperial University of Kyoto-though it is several hundred miles from it-has only been established recently. So far, no publications have issued from it, though a good deal of work is in hand. The laboratory is situated in one of the principal hot-spring regions of Japan. The work undertaken there consists of researches into changes of level, temperature, hydrogen and chlorine ion content, and electrical conductivity of the hotspring waters. Micro-seismographs magnifying fifty thousand times are to be seen there, and the institution is undoubtedly being established at Beppu on $a$ very broad and valuable basis. Indeed, it might form a better model upon which to establish our own proposed vulcanological station than the Hawaiian Vulcanological Observatory. The latter is, perhaps, more concerned with activities of a living volcano, whereas this Geophysical Laboratory is in a region not very unlike Rotorua, although perhaps of rather less activity than Rotorua. Dr. Shida, of the Geophysical Department of the Kyoto University, is in charge of the laboratory, and many of the instruments in use in it are of his own design.

RESEARCH IN JAPAN.--What I have said refers to the institutions that I was able-in the exceedingly short time available-to visit. I am afraid it gives a most imperfect idea of the work that is going on in them, and it certainly gives no idea of the amount of research in progress in Japan. Besides the work at institutions solely intended for research purposesand to deal at all with these would need a volume rather than a short report-besides these an immense amount of first-class research work is done at the universities themselves. There are forty-five government or municipal research institutions in Japan. As well as these, there are twenty-five other institutions either privately endowed or maintained by business firms (one of these is the Institute of Physical and Chemical Research already referred to), and this number does not include observatories, of which there are many. The average number of research 'experts' employed in these institutions is about twenty, which number does not include those who are classed as 'assistants' and are very much more numerous, probably at least double as many.

No. 2993, VoL. 119] 
The Imperial UNIVERSITIES.-There are six of these, namely, Tokyo, Kyoto, Tohoku (at Sendai), Kyushu at Fukuoka, Hokkaido, and Keijo. There are also other universities, known as private universities. The staffing of these universities is to a New Zealander exceedingly liberal, but it accounts for much that it would be otherwise impossible to explain. The Tokyo University, besides teaching its students, or rather perhaps as an aid to teaching its students, maintains the following institutions: (a) The Tokyo Astronomical Observatory; (b) the Earthquake Research Institute; (c) the Aeronautical Research Institute; $(d)$ the Institute for Infectious Diseases; $(e)$ the Seismological Institute ; $(f)$ the Botanic Garden; $(g)$ the Marine Biological Station; as well (evidently) as some others.

The Kyoto University has associated with it : $(a)$ The Astronomical Observatory; (b) the Kamigamo Seismological Station; (c) the Beppu Geophysical Laboratory; (d) the Seto Marine Station; and $(e)$ the Otsu Hydro-Biological Station. These are, of course, in addition to the usual laboratories which are to be found in every modern university.

The general policy and mode of working of these universities can perhaps be seen from considering one department in one of them, and the one I naturally choose is that of physics at Kyoto. The Department of Physics is divided into three sub-departments, namely, (a) physics; (b) cosmical physics ; and $(c)$ geophysics. The sub-branch physics has in it four professors, three assistant professors, and two lecturers, and I was informed that there are less than 60 students taking the subject. The sub-branch cosmical physics has two professors and two lecturers. The sub-branch geophysics has three professors, two assistant professors, and nine lecturers. The liberal scale of staffing is thus apparent, and amounts in the sub-branch physics to less than seven students per teacher. The students enter the University at the average age of about twenty-two years. Such a system produces first-class men, and, moreover, so restricts the field of study of the professor or teacher that he is enabled. to be really an expert in his branch, rather than a man who perhaps knows something of many branches and knows none of them well.

The cost is of course proportionally high, but that Japan finds that it pays is shown by the figures relating to the Kyoto University, which are taken from the Kyoto University Calendar for 1926. The University is a very modern institution, only boasting twenty-nine years of existence-it was founded in 1897. The cost of it during that year was approximately $£ 5400$, whereas during the year 1926 it was $£ 500,000$. As there are something a little under 4000 students at the University (in all grades), this cost is about $£ 125$ per student per annum at present. In the whole Department of Science in the University of Kyoto there are 85 teachers. To cover the same work in Canterbury College we have about ten teachers. The number of students in this Department in Kyoto is 250, which is probably about what it is in Canterbury College-indeed, it may be more at the latter place.

The same kind of thing holds in every department of all the six Imperial universities of Japan. Japan has realised that the thorough education--specialist education, of course, in every case-of a comparatively few is more the function of the university, and pays the nation better than the cheap sort of education of a great many. Perhaps I may quote from an Imperial ordinance governing universities which was promulgated in 1918. Art. 1 of that ordinance gives a concise statement of the functions of a university as conceived in Japan. It reads: "Universities shall have for their objects the teaching of such sciences, theoretical and practical, as are required for the purposes of the State, and the prosecution of original research in the said sciences; and consideration shall be given to refinement of character with an eye to fostering national ideas." A narrow view of the word "sciences" as used above is not taken, and Art. 2 specifies the departments which may be set up, of which "Literature" is one.

It is no doubt in the spirit of this ordinance that the universities of Japan are such centres of research. They have realised, as some one once put it, that "the function of a university is not to teach," but that it also has the further function of learning as well, and that by learning, teaching is best done. These universities have therefore established such places as the Aeronautical Research Institute and the Beppu Geophysical Laborajory, to which reference has already been made, as well as many other institutions of an analogous sort, and it is to these that the students are drafted as they become more proficient in their work, and they see the work done there as it is done in actual practice, and they advance knowledge at the same time.

In conclusion, I may perhaps refer to an opinion which was expressed to me by one of the Overseas delegates having special knowledge of the interaction of science and industry. He told me that he thought that the organisation of the co-operation of the two is more complete in Japan than in any other of the many countries he has visited (which included Eng. land, France, the United States, Czechoslovakia, and Germany), with the exception of one of them, which, so far as I remember, is Germany. Thus the work started in the 'seventies by Ewing and Ayrton and Perry has borne rich fruit for this progressive Empire.

\section{The Diffusion of Culture.}

THE Frazer Lecture was delivered at Cambridge by Dr. R. R. Marett, reader in social anthropology in the University of Oxford, on Mar. 2. Dr. Marett, taking "The Diffusion of Culture" as his subject, dealt chiefly with the views of Prof. Elliot Smith, whether as expressed positively or as implied in the criticism of rival doctrines. Thus as a critic he stigmatised Tylor's animism as mere guess-work which defies the known facts. Again, he regards "The Golden Bough," however learned, as based on a fallacy and as amounting to nonsense because it does not follow the historical method. The reply to these criticisms seems to be that the whole virtue of scientific method consists in being "sufficient unto the day." To require that what may be proved now might just as well have been proved fifty years ago is to ignore the historical conditions that determine movement of thought. In view of the immense stimulus given to research, no less in the field than in the study, by the working hypotheses carefully formulated as such by Tylor and Frazer, it is absurd to accuse them of having laboured in vain. In short, the critic seems to be deficient in that historic sense which he desiderates in others.

Turning from the polemics to the positive tenets of the diffusionist school, Dr. Marett distinguished between the special question of whether Egypt could be shown to be the sole originator of civilisation and the general question whether a diffusionist method is capable of taking entire charge of cultural anthropology. The evidence for and against the claims of Egypt as the cradle-land of civilisation

No. 2993, VoL. 119] 